\title{
On the incidence of fits and mental retardation in tuberous sclerosis
}

\author{
D W Webb, A E Fryer, J P Osborne
}

\begin{abstract}
Objectives-To establish the frequency of fits and mental retardation in an unbiased group of tuberous sclerosis patients.

Methods-Known tuberous sclerosis families with more than one affected person were ascertained for a genetic linkage study. A number of members were born after genetic counselling had been given after identification of the proband. These subjects were then carefully examined clinically and in many cases with cranial computerised tomography, renal ultrasound, and skeletal survey but not echocardiography. They provide an unbiased group of tuberous sclerosis patients and allow affected patients with normal intellect to be diagnosed.

Patients-Thirty-seven tuberous sclerosis families were ascertained and 26 patients born after the family proband were identified.

Results-Sixteen of these 26 patients suffered fits (62\%) and 10 patients were mentally retarded (38\%). Conclusions-A lower incidence of fits and mental retardation has been found in an unbiased sample of tuberous sclerosis patients. The lifetime risk for fits might be higher had we been able to follow the patients for longer. However, we believe these are more appropriate figures to use in genetic counselling for this disease.
\end{abstract}

Early reports of tuberous sclerosis focused quite reasonably on the serious neurological manifestations of the disease. The diagnosis was rarely made in the absence of fits, mental retardation, and facial angiofibromas, a triad which for a time became synonymous with the disease itself. ${ }^{1}$ For these reasons early calculations of the disease prevalence were underestimated, based as they were on the frequency of the diagnosis in mental institutions and an extrapolation of these figures to the general population. ${ }^{2-4}$

Bath Unit for Research into Paediatrics, Royal United Hospital, Combe Park, Bath, Avon BAl 3NG. D W Webb, A E Fryer, J P Osborne

Correspondence to Dr Osborne.

Received for publication 6 July 1990

Revised version accepted for publication 6 November 1990.
The development of improved imaging techniques capable of detecting subtle manifestations of the disease and their application in assessment, particularly of asymptomatic first degree relatives, has forced us to review the disease prevalence and therefore the frequency of complications. Population based studies are likely to be more accurate if first degree relatives of identified cases are carefully examined. They are still likely to fall short of complete ascertainment because approximately $70 \%$ of cases are spontaneous mutations who do not always present to medical care.

Within studies of observed prevalence of tuberous sclerosis the frequency of neurological sequelae has ranged from 50 to $93 \%$ for fits and from 25 to $87 \%$ for mental retardation. ${ }^{5-9}$ Three of these studies involved fewer than 15 patients and the only study with more than 20 patients found a frequency of $68 \%$ for mental handicap; the frequency of fits was not reported. We would like to report a new frequency for the neurological complications of tuberous sclerosis in an unbiased sample of affected subjects.

\section{Methods}

Tuberous sclerosis families with more than one affected person were ascertained for a genetic linkage study. ${ }^{10}$ All family members were assessed by the same doctor who was experienced in examining tuberous sclerosis patients, using Wood's light and direct fundoscopy. In many cases they were also examined using cranial computerised tomography, renal ultrasound, and skeletal survey but not echocardiography. The criteria for diagnosis were based on those suggested by Gomez and modified by Osborne. ${ }^{11} 12$

A number of members were born after genetic counselling had been given after identification of the proband. By identifying those affected among this group we were provided with an unbiased sample of tuberous sclerosis patients from which the frequency of neurological complications could be assessed.

Two years after their first examination the families were contacted again and interviewed about the developmental progress of the younger children and school or work progress in the older patients. Where necessary further information was obtained from 
educational psychologists and physicians involved in the patients' care.

The degree of mental handicap was assessed on the patients' ability to walk, talk, read, and write and undertake self-care (dressing, feeding, and toileting).

\section{Results}

Thirty-seven families were identified for genetic linkage. There were 138 family members affected and 26 were born after the family proband was diagnosed. Sixteen $(62 \%)$ suffered fits at some time $(95 \%$ confidence intervals $=50$ to $79 \%)$. Ten patients $(38 \%)$ were mentally retarded $(95 \%$ confidence intervals $=19$ to $56 \%$ ). Five of these were severely handicapped, being unable to walk or talk and requiring complete care. Four were mild to moderately handicapped being able to walk, hold reasonable conversation, and undertake most self-care, but except for one boy were unable to read and write. This boy attended special school because of learning difficulties and severe behaviour problems. The youngest child is six months behind by Griffiths developmental assessment at 2 years of age.

In the group with normal intellect the two youngest children have had normal developmental assessments at 4 years of age. The other patients are all either attending normal school or are gainfully employed.

All those with mental retardation had suffered fits and the mean age of onset by history was 10 months (range 1 to 30 months) compared with 28 months (range 3 to 96 months) for those with normal intellect.

Table 1 Clinical features of 26 patients born after the family probands.

\begin{tabular}{|c|c|c|c|c|c|}
\hline No & Sex & $\begin{array}{l}\text { Age } \\
(y)\end{array}$ & Fits & $\begin{array}{l}\text { Onset } \\
\text { (mth) }\end{array}$ & $\begin{array}{c}\text { Mental } \\
\text { handicap }\end{array}$ \\
\hline $\begin{array}{r}1 \\
2 \\
3 \\
4 \\
5 \\
6 \\
7 \\
8 \\
9 \\
10 \\
11 \\
12 \\
13 \\
14 \\
15 \\
16 \\
17 \\
18 \\
19 \\
20 \\
21 \\
22 \\
23 \\
24 \\
25 \\
26\end{array}$ & $\begin{array}{l}\mathbf{M} \\
\mathbf{M} \\
\mathbf{M} \\
\mathbf{M} \\
\mathbf{M} \\
\mathbf{M} \\
\mathbf{M} \\
\mathbf{F} \\
\mathbf{F} \\
\mathbf{M} \\
\mathbf{M} \\
\mathbf{M} \\
\mathbf{F} \\
\mathbf{M} \\
\mathbf{F} \\
\mathbf{F} \\
\mathbf{M} \\
\mathbf{M} \\
\mathbf{M} \\
\mathbf{M} \\
\mathbf{M} \\
\mathbf{F} \\
\mathbf{F} \\
\mathbf{M} \\
\mathbf{M} \\
\mathbf{M}\end{array}$ & $\begin{array}{r}2 \\
6 \\
7 \\
9 \\
9 \\
10 \\
11 \\
18 \\
24 \\
24 \\
4 \\
5 \\
6 \\
6 \\
7 \\
8 \\
8 \\
8 \\
9 \\
9 \\
12 \\
16 \\
16 \\
21 \\
25 \\
29\end{array}$ & $\begin{array}{l}+ \\
+ \\
+ \\
+ \\
+ \\
+ \\
+ \\
+ \\
+ \\
+ \\
+ \\
+ \\
- \\
- \\
- \\
- \\
- \\
+ \\
- \\
+ \\
- \\
+ \\
- \\
+\end{array}$ & $\begin{array}{r}13 \\
18 \\
3 \\
18 \\
1 \\
9 \\
30 \\
6 \\
6 \\
3 \\
11 \\
36 \\
- \\
- \\
- \\
- \\
- \\
- \\
96 \\
- \\
8 \\
- \\
-3 \\
- \\
15\end{array}$ & $\begin{array}{l}\quad+ \\
\text { Moderate } \\
\text { Severe } \\
\text { Severe } \\
\text { Moderate } \\
\text { Moderate } \\
\text { Severe } \\
\text { Severe } \\
\text { Severe } \\
\text { Moderate } \\
\text { - } \\
\text { - } \\
\text { - } \\
\text { - } \\
\text { - } \\
\text { - } \\
\text { - } \\
\text { - } \\
\text { - } \\
\text { - } \\
\text { - } \\
\text { - } \\
\text { - } \\
\text { - } \\
\text { - } \\
\text { - }\end{array}$ \\
\hline
\end{tabular}

Table 2 The frequency of fits and mental retardation in hospital and population based studies.

\begin{tabular}{lclcc}
\hline Reference & Date & $\begin{array}{c}\text { Fits } \\
(\%)\end{array}$ & $\begin{array}{c}\text { Mental } \\
\text { retardation } \\
(\%)\end{array}$ & $\begin{array}{c}\text { Total } \\
\text { No }\end{array}$ \\
\hline Hospital based & 1932 & 93 & 100 & 29 \\
14 & 1935 & - & 100 & 20 \\
2 & 1967 & 93 & 60 & 71 \\
11 & 1968 & $82 \cdot 5$ & 70 & 40 \\
4 & 1969 & 89 & 63 & 71 \\
15 & 1976 & 98 & 88 & 100 \\
16 & 1981 & 83 & 79 & 62 \\
17 & & & & 8 \\
Population based & 1956 & 87 & 87 & 18 \\
5 & 1968 & 83 & 61 & 68 \\
6 & 1984 & - & 68 & 8 \\
7 & 1985 & 50 & 25 & 14 \\
8 & 1989 & 93 & 85 & 26 \\
9 & 1990 & 62 & 38 & 8 \\
\hline This family study & 199 & & \\
\hline
\end{tabular}

Five patients $(50 \%)$ with mental handicap had a history of infantile spasms and four of these were severely retarded. One patient in the intellectually normal group had also had infantile spasms.

The salient clinical features of the 26 patients are outlined in table 1 . Among the family probands, $72 \%$ suffered fits and $53 \%$ were mentally retarded.

\section{Discussion}

The prevalence of mental retardation and fits in tuberous sclerosis in what we believe to be an unbiased group of patients is lower than in earlier reports. A review of previous studies in which prevalence figures for neurological complications are included is outlined in table 2 . Only one population based study was large enough to give accurate figures on the frequency of mental retardation. ${ }^{7}$ Details of the classification of mental handicap is lacking in this report. The prevalence of fits is consistently greater than $80 \%$ except in one report of only eight cases. ${ }^{8}$

It is our experience that tuberous sclerosis does not cause mental retardation in the absence of fits. Indeed, if fits are avoided in the first one to two years of life subsequent mental retardation is rare. As the youngest children in the group with normal intellect (cases 11 and 12) are now over 4 years, the calculated frequency of mental handicap should be reliable. The life time risk for fits might be higher had we been able to follow the patients for longer.

One child in the group with mental handicap (case 7) was first noted to be having fits at $2^{1 / 2}$ years of age. On review of his developmental history his early speech was greatly delayed (despite normal hearing) implying a degree of developmental delay in the absence of fits. This finding is so unusual that it raises the possibility of either other contributing factors to 
his handicap or the presence of fits at an earlier age that were not recognised. The age of onset of fits for all these patients is also subject to this bias.

We would like to have given a more detailed account of the types of fits found. Our information on fit type is based on history alone. We feel that this is likely to be reasonably accurate for infantile spasms but we cannot be sure that those patients who are described as having generalised tonic-clonic seizures are not actually having complex partial seizures.

There is now evidence for genetic heterogeneity in tuberous sclerosis. ${ }^{13}$ No evidence of phenotypic heterogeneity has yet been found. The possibility that familial and sporadic tuberous sclerosis are different diseases might explain our results. However, the finding that $72 \%$ of the family probands suffered fits and $53 \%$ were mentally retarded is not very different from that expected in sporadic cases or from our own experience in Wessex. Even if there are phenotypic differences between family and sporadic cases it would seem preferable when giving genetic advice to base recurrence risks for disease complications on information gleaned from family studies and not from sporadic cases.

In the recent past we have used recurrence risks of $80 \%$ for fits and $50 \%$ for mental retardation when counselling families. We propose that in giving genetic advice to patients with tuberous sclerosis, this lower frequency for mental retardation (38\%) should be used. The frequency for fits is probably close to $62 \%$.

We would like to thank the physicians who contributed patients for the gene linkage study. We would also like to thank the Tuberous Sclerosis Association, Glaxo Laboratories Ltd, Avon Rubber plc, Intercity, and Cow and Gate Ltd for their financial support and Helen Hansen for her help with typing the manuscript.

1 Vogt H. Zur Diagnostik der tuberosen sklerose. Z Erforsch Behandl fugendl Schwachsinns 1908;2:1-12.

2 Gunther M, Penrose LS. The genetics of epiloia. $f$ Genet 1935;31:413-30.

3 Ross AT, Dickerson WW. Tuberous sclerosis. Arch Neurol Psychiatry 1943;50:233-57.

4 Zaremba J. Tuberous sclerosis: a clinical and genetical investigation. $\mathcal{F}$ Ment Defic Res 1968;12:63-80.

5 Stevenson AC, Fischer OD. Frequency of epiloia in Northern Ireland. $\mathrm{Br} \mathcal{F}$ Prev Soc Med 1956;10:134-5.

6 Nevin NC, Pearce WG. Diagnostic and genetical aspects of tuberous sclerosis. J Med Genet 1968;5:273-80.

7 Hunt A, Lindenbaum RH. Tuberous sclerosis: a new estimate of prevalence within the Oxford region. F Med Genet 1984;4: 272-7.

8 Wiederholt WC; Gomez MR, Kurland LT. Incidence and prevalence of tuberous sclerosis in Rochester, Minnesota, 1950 through 1982. Neurology 1985;35:600-3.

9 Umapathy D, Johnston AW. Tuberous sclerosis: prevalence in the Grampian Region of Scotland. F Ment Defic Res 1989;33: 349-55.

10 Fryer AE, Chalmers A, Connor JM, et al. Evidence that the gene for tuberous sclerosis is on chromosome 9. Lancet 1987;i: 659-61.

11 Gomez MR, ed. Tuberous sclerosis. New York: Raven Press, 1979.

12 Osborne JP. Diagnosis of tuberous sclerosis. Arch Dis Child 1988;63:1423-5.

13 Amos J, Bech-Hansen T, Burley MM, et al. Linkage heterogeneity in tuberous sclerosis. Tuberous sclerosis collaborative group. HGM10. Cytogenet Cell Genet 1989;51:1010.

14 Critchley M, Earl CJC. Tuberous sclerosis and allied conditions. Brain 1932;55:311-44.

15 Bundey S, Evans K. Tuberous sclerosis: a genetic study. F Neurol Neurosurg Psychiatry 1969;32:591-603.

16 Pampiglione G, Moynahan EJ. The tuberous sclerosis syndromeclinical and EEG studies in 100 children. $\mathcal{F}$ Neurol Neurosurg Psychiatry 1976;39:666-73.

17 Monaghan HP, Krafchik BR, MacGregor DL, Fitz CR. Tuberous sclerosis complex in children. Am $\mathcal{F}$ Dis Child 1981;135:912-7. 